\title{
The tobacco settlement: an analysis of newspaper coverage of a national policy debate, 1997-98
}

\author{
Julie C Lima, Michael Siegel
}

\begin{abstract}
Objective-To examine the framing of tobacco policy issues in the news media during the national tobacco settlement debate of 1997-98. The major aims were (1) to describe the extent of newspaper coverage of each of the specific components of the proposed tobacco settlement; (2) to identify the tobacco control frames, and the dominant frame, appearing in each newspaper article; and (3) to examine trends in tobacco control frames over time.
\end{abstract}

Design-A content analysis was performed on 117 articles related to national tobacco legislation appearing in the Washington Post from 1 January 1997 through 18 June 1998.

Main outcome measures-(1) Major policy themes of the settlement referred to or implied in each article; (2) major frames used to discuss the problem of tobacco in each article.

Results-The generation of new revenue was the dominant theme of the articles, appearing as a major focus in $44 \%$ (52) of the articles. Other than the issues of Food and Drug Administration regulation of tobacco and restrictions on cigarette advertising, the public health policy aspects of the tobacco settlement received little attention. The problem of tobacco was portrayed as one of youth smoking in $55 \%$ (64) of the articles, but as one of a deadly product in none of the articles.

Conclusions-Future discussions of comprehensive tobacco policy should be driven by a more specific discussion of the precise programme and policy mechanisms by which tobacco use can be most effectively prevented and controlled. The public health community must find ways to frame the tobacco issue more broadly than simply as one of youth smoking. (Tobacco Control 1999;8:247-253)

Keywords: legislation; newspapers; public policy

The national tobacco policy debate that occurred during 1997 and 1998 may have been the most important tobacco policy debate in recent history. For perhaps the first time, tobacco was in the newspaper headlines almost daily for nearly an entire year. The issue of tobacco was placed squarely on the national media, policy, and public agendas. The debate over a national tobacco settlement may have implications for the tobacco control movement that go far beyond the immediate result: failure to secure comprehensive Congressional tobacco legislation. This issue may play a role in framing the debate over tobacco policy and tobacco control interventions, both in the public health community and in the eyes of policy makers and the public, for many years to come.

The widespread media coverage of the tobacco policy debate not only placed the tobacco issue on the public's agenda, but helped to define the way the public thinks about tobacco as a public health problem. Regardless of the result of the proposed legislation, the media coverage of the debate will itself help shape the way the tobacco issue will be defined in the future. The framing of the debate-or the way in which arguments were crafted to define the problem of tobacco in the debate-not only suggests to policy makers and the public why the problem of tobacco is important, but defines the appropriate solutions to the tobacco problem. In other words, the media tell people not only what issues to think about, but how to think about them.

Given the magnitude of the potential influence that media coverage of the tobacco settlement debate may have on the American public, it is important to examine how the tobacco issue was framed in the media during the tobacco settlement debate of 1997-98.

The media's influence on the way the public thinks about a public health issue is a result of the framing of that issue. ${ }^{1-9} \mathrm{~A}$ frame is a way of "packaging and positioning an issue so that it conveys a certain meaning." 1 Framing is the emphasis placed around particular issues "that seeks to define "what this issue is really about." " The way in which a public health issue is framed affects public opinion, ${ }^{10-14}$ influences individual behaviour, ${ }^{15-19}$ and plays a central role in the process of public health policy formation. ${ }^{1-3} 20$ Framing of tobacco control issues in the media has been shown to influence the legislative debate over tobacco control policies. ${ }^{120}$

Because the media coverage of the tobacco policy debate of 1997-98 was so extensive, the way in which the tobacco problem was framed during this debate may influence tobacco policy formation in the future. The solutions to
Received 29 October 1998 1999

Accepted 15 April 1999 
the problem that are implied by the frames used in the debate may serve as the basis for the future policy agenda. Moreover, solutions that stem from frames that were not used in the debate may not surface on the policy agenda.

In this paper we present the results of a content analysis of articles about the national tobacco settlement appearing in the front section of the Washington Post during the 18 months preceding the ultimate defeat of the proposed legislation on 18 June 1998. Our major aims were: (1) to describe the extent of newspaper coverage of each of the specific components of the proposed tobacco settlement (for example, cigarette tax increase, tobacco industry penalties, Food and Drug Administration (FDA) authority to regulate tobacco, tobacco industry immunity); (2) to identify the tobacco control frames, and the dominant frame, appearing in each newspaper article; and (3) to examine trends in tobacco framing by comparing the identified tobacco frames with frames appearing in tobacco policy related newspaper articles during the period 1985-96. To the best of our knowledge, this is the first content analysis of the newspaper coverage of the tobacco settlement.

We are aware of only two previous content analyses of newspaper stories related to the tobacco issue. $^{121}$ Chapman studied 1601 articles mentioning tobacco or smoking in 30 Australian capital city newspapers in 1987-88 to determine how differently the issue of smoking was portrayed by newspapers with different ownership. ${ }^{21}$ Menashe and Siegel reviewed 179 front page articles from the Washington Post and New York Times during the period 1985-96. ${ }^{1}$ They identified the major tobacco policy frames used by the tobacco industry and by public health advocates during the past decade and concluded that although the tobacco industry has developed a consistent and powerful set of frames over this period, public health professionals have not. The identification and characterisation of tobacco policy frames during the period 1985-96 provides a useful comparison for the current analysis.

\section{Methods}

BACKGROUND: THE TOBACCO SETTLEMENT

The tobacco settlement originated from negotiations between the state attorneys general, tobacco plaintiffs' attorneys, and tobacco industry attorneys that occurred between 3 April and 20 June 1997. ${ }^{22-24}$ On 20 June 1997, a tobacco settlement was announced. ${ }^{23}{ }^{25}$ The settlement was presented to Congress, and its provisions were debated, beginning on 26 June 1997. ${ }^{26}$ Several bills were introduced into Congress to codify the provisions of the tobacco settlement. Other bills were introduced that contained alternative proposals. Eventually, the bill introduced by Senator John $\mathrm{McCain}^{27}$ became the chief platform on which the tobacco settlement was debated in the US Senate. On 17 June 1998, the Senate failed twice on procedural votes to invoke cloture on the McCain bill and advance it to a final Senate floor vote. ${ }^{28}$ Although President Clinton and some legislators still talked of reviving the bill, the chances for comprehensive national tobacco legislation to emerge during the 1998 congressional session were, at this point, unlikely.

SAMPLING

In order to obtain the most comprehensive information on the framing of the tobacco settlement debate in the media, we decided to take a complete sample of news articles from the nation's leading newspaper that covers national policy issues: the Washington Post. Although the New York Times is also an important media outlet, we decided not to sample articles from the Times for three reasons. First, although the Washington Post provided nearly day by day coverage of the tobacco settlement debate and covered nearly every aspect of the debate, the New York Times provided only sporadic coverage, and only covered some of the issues that were discussed in Congress. We felt that the best way to obtain a comprehensive idea of the full scope of issues as they were portrayed by the media was to obtain a complete sample of news articles from the Washington Post. Second, because of the intensive nature of the content analysis process, we could not possibly sample every article from both the Washington Post and New York Times. We decided that the advantages of sampling completely from the Post outweighed the advantages of including articles from both papers, but only being able to review a random sample of these articles. We felt that a full understanding of the way in which the Washington Post covered the tobacco settlement debate would provide more important and complete information than a mere sampling of the way a variety of newspapers covered the debate. Third, it is the Washington Post, not the New York Times, that is most widely read by policy makers in Washington and that most influences congressional policy debate on a daily basis. An understanding of the way the tobacco settlement was covered in the Post would provide a reasonable understanding of the way policy makers in Washington perceived the issues involved in the tobacco settlement debate.

We analysed the content of articles appearing in the front section of the Washington Post between 1 January 1997 and 18 June 1998. We chose 1 January 1997 as a starting point to be sure that we included all articles covering issues that led to the initiation of tobacco settlement negotiations. We chose 18 June 1998 as an ending point because it included articles related to the final defeat of the comprehensive tobacco legislation on 17 June.

We searched the Washington Post using Lexis Nexis. Inclusion criteria for articles were: (1) time period: 1 January 1997 to 18 June 1998 (inclusive); (2) location: articles appearing in section $\mathrm{A}$; and (3) content: articles must have contained the word "tobacco" in the headline. This search protocol proved to be more comprehensive than other methods, including searching for articles with the word "tobacco settlement" anywhere in the text, or with the word "tobacco" appearing at least five times 
throughout the body of the article. Using this method, 272 articles were retrieved.

Exclusion criteria were editorials and op-ed pieces (38 articles) and articles not clearly related to the national tobacco settlement or to the formulation of national tobacco policy (117 articles). The final sample consisted of 117 articles.

We excluded editorials and op-ed pieces because we were interested specifically in how the media were framing the tobacco settlement debate in their primary news coverage, not in how editorial boards and commentators were framing the debate. This is certainly an important question, but we wanted to separate this issue out from the analysis of actual news articles.

We limited the analysis to articles from section A simply for logistical reasons: this is where the Washington Post placed articles on the tobacco settlement debate. This limitation made it easier for us to identify the relevant articles.

\section{CODING}

Each of the 117 articles was read by two reviewers (JCL and MS) and analysed for major policy themes of the settlement referred to or implied in the article and major frames used to define the problem of tobacco in the article.

The themes refer to the actual policy components of the tobacco legislation being discussed. These were coded from a list that was designed based on the aspects of the original tobacco settlement as announced on 20 June 1997. These themes included the following: (1) generation of new revenue; (2) increase in cigarette taxes or prices; (3) tobacco industry monetary penalties; (4) FDA authority to regulate tobacco; (5) restrictions on cigarette advertising and promotion; (6) reduction of youth access to tobacco products; (7) allocation of revenue for national, antismoking campaigns; (8) adult smoking cessation programmes; (9) policies to reduce exposure to secondhand smoke; (10) support for tobacco farmers; (11) general discussion of immunity from legal actions for tobacco companies; (12) prohibition of class action lawsuits against the tobacco industry; (13) elimination of punitive damages in future lawsuits against the tobacco industry; (14) elimination of future third party payer claims against the tobacco companies; and (15) annual caps on tobacco company legal liability.

We each identified all of the above themes that were referred to in each article, or that were implied as being a key component of the legislation or policies being discussed. A final list of themes that could be considered the central policy themes for each article was constructed by including only those themes listed as being present by both reviewers. We then decided, by mutual agreement, whether each identified theme could be considered to be a "major focus" of the news article. Generally, themes were considered to be a major focus of an article if they appeared in the headline or within the first few paragraphs of an article.

In addition to identifying the central policy themes for each article, one author recorded the total number of mentions of each of the 15 policy themes in the article, and the number of mentions appearing in the headline or first four paragraphs.

Another focus of the analysis was to categorise the articles into groups based on their tobacco control frames (the way the articles defined the problem of tobacco). Tobacco control frames were adopted from the previous analysis by Menashe and Siegel. ${ }^{1}$ These frames were designed to capture the major arguments for tobacco policies, expressed as a coherent set of thematic arguments linked by a common core position, definition of the tobacco problem, metaphor, symbol, images, catch phrases, and implied solution to the tobacco problem. ${ }^{1}$ The frames were identified from articles appearing in the Washington Post and the New York Times during the period 1985-96, and included the following nine frames and core positions: Kids-tobacco is a problem because minors shouldn't smoke. Killer/ corporate liability - tobacco is a problem because it is a deadly drug and kills more than 400000 Americans each year. Drug delivery device - tobacco is a problem because nicotine is an addictive drug and cigarette companies manipulate the levels of nicotine in cigarettes to addict smokers to their products. Costs of smoking - tobacco is a problem because it costs society large amounts of money in health care costs and lost productivity. David v Goliath-tobacco is a problem because the companies are corporate giants with vast resources who are being fought by small public health organisations with few resources. Outside intruder - tobacco is a problem because the tobacco industry interferes in the lawmaking process by lobbying, donating large amounts of money to members of Congress, and using its special interest influence. Smokers at risk - tobacco is a problem because smoking in itself is harmful. Deceit/manipulationtobacco is a problem because the companies are manipulating people to smoke through their deceptive advertising, lying to people, and deceiving people about the health effects of tobacco. Non-smokers' rights-tobacco is a problem because secondhand smoke is killing people.

We each identified all tobacco control frames appearing in every article. In addition, each author designated one frame as the dominant tobacco control frame for the article. This was a subjective decision based on what single frame best characterised the way the tobacco problem was portrayed in the article. If no frame appeared in the article, the reviewers noted this. We compiled a final list of frames appearing in each article by combining the lists of the two reviewers. Thus any frame that was coded by one or the other of the reviewers as appearing in the article was considered to be present. 
To identify the one dominant frame in each article, we noted any discrepancies in the dominant frames noted by the reviewers and resolved these discrepancies to the satisfaction of both reviewers. Discrepancies in the coding of the dominant frame were present in approximately 33 of the 117 articles. We were able to reach complete agreement on the dominant frames in each article with only minimal discussion.

Because there were many more themes present in the articles than frames, we decided to require both reviewers to identify a theme in order to list it in the final coding, whereas we required only one reviewer to identify a frame in order to list it in the final coding.

\section{Results}

THEMES

The focus of the settlement, as portrayed to the American public in the Washington Post articles, was money. New revenue was the most frequent theme of the articles, appearing as a major focus of the policy debate in $44 \%$ (52) of the 117 articles (table 1). The theme of new revenue was mentioned 269 times in the 117 articles; 73 of these mentions (27\%) appeared in the headline or first four paragraphs. The theme of increases in cigarette taxes/prices was the third most common major policy focus of the articles, appearing as a major focus of the policy debate in $32 \%$ (38) of the articles. The theme of increases in cigarette taxes/prices was mentioned 191 times in the articles; 46 of these mentions (24\%) appeared in the headline or first four paragraphs.

The theme of tobacco industry immunity appeared as a major policy focus in 33\% (39) of the articles (table 1). The general immunity theme was mentioned 180 times; 53 (30\%) of these mentions occurred in the headline or first four paragraphs. Although the general issue of immunity was a major theme in the articles, it is important to note that the specific aspects of tobacco industry immunity (that is, prohibition of class action lawsuits, elimination of punitive damages, prohibition of third party payer suits, and annual liability caps) were rarely mentioned in the articles. The theme of class action lawsuit restrictions appeared as a major focus in only $3 \%$ (3) of the articles, the theme of elimination of punitive damages appeared as a major focus in only $5 \%(6)$, annual liability caps appeared as a major focus in only $4 \%$ (5) of the articles, and prohibition of third party payer suits did not appear as a major focus in any article. In addition, the specific aspects of tobacco industry immunity were less likely to appear in the headline or first four paragraphs of the articles. The total numbers of mentions in the headline or first four paragraphs were 2 for class action lawsuits, 10 for punitive damages, 12 for liability caps, and 0 for third party payer suits.

Of the actual public health policy issues in the tobacco settlement, only FDA regulatory authority and restrictions on cigarette advertising appeared in a substantial number of articles (table 1). The issue of FDA authority appeared as a major focus in $26 \%$ (31) of the articles and the theme of cigarette advertising restrictions appeared as a major focus in $22 \%$ (26) of the articles. Public health policy issues such as youth access (3\%), allocation of revenue for anti-smoking campaigns (4\%), secondhand smoke (3\%), and adult cessation ( $2 \%$ ) were found to be a main theme in only a small percentage of the articles.

FRAMES

The problem of tobacco use, as portrayed to the American public in the Washington Post articles, was one of youth smoking. The kids frame appeared in $81 \%$ (95) of the 117 articles, and this frame was the dominant frame in 55\% (64) of the articles (table 2). No other frame was close to the kids frame in terms of either the percentage of articles in which it appeared or the percentage of articles in which it was the dominant frame. The next most common frame appearing in the articles was the David v Goliath frame, which appeared in only 35\% (41) of the articles, and appeared as the dominant frame in only $9 \%$ (11) of the articles.

The killer/corporate liability frame and the non-smokers' rights frame failed to appear as the dominant frame in any of the 117 articles (table 2). These were the least common frames appearing in the articles. The killer/corporate liability frame appeared in only $15 \%$ (17) of

Table 1 Major policy themes in newspaper coverage of the tobacco settlement debate, 1997-98

\begin{tabular}{|c|c|c|c|c|c|}
\hline Theme* & $\begin{array}{l}\text { Number of times } \\
\text { mentioned }\end{array}$ & $\begin{array}{l}\text { Number of mentions } \\
\text { in headline or first } \\
\text { four paragraphs }\end{array}$ & $\begin{array}{l}\text { Percentage of all mentions } \\
\text { appearing in headline or } \\
\text { first four paragraphs }\end{array}$ & $\begin{array}{l}\text { Number of times } \\
\text { theme appeared as } \\
\text { major focus of article }\end{array}$ & $\begin{array}{l}\text { Percentage of articles in } \\
\text { which theme appeared } \\
\text { as major focus }\end{array}$ \\
\hline \multicolumn{6}{|l|}{ Public health policy aspects } \\
\hline FDA authority & 138 & 45 & $33 \%$ & 31 & $26 \%$ \\
\hline Advertising restrictions & 76 & 16 & $21 \%$ & 26 & $22 \%$ \\
\hline Allocation of revenue for antismoking campaign & 28 & 4 & $14 \%$ & 5 & $4 \%$ \\
\hline Secondhand smoke & 13 & 3 & $23 \%$ & 4 & $3 \%$ \\
\hline Youth access & 12 & 5 & $42 \%$ & 4 & $3 \%$ \\
\hline Adult cessation & 11 & 2 & $18 \%$ & 2 & $2 \%$ \\
\hline \multicolumn{6}{|l|}{ Financial aspects } \\
\hline Generation of new revenue & 269 & 73 & $27 \%$ & 52 & $44 \%$ \\
\hline Cigarette tax/price increase & 191 & 46 & $24 \%$ & 38 & $32 \%$ \\
\hline Industry payments/penalties & 67 & 14 & $21 \%$ & 12 & $10 \%$ \\
\hline Farmer support & 56 & 16 & $29 \%$ & 8 & $7 \%$ \\
\hline \multicolumn{6}{|l|}{ Civil justice aspects } \\
\hline Immunity in general & 180 & 53 & $30 \%$ & 39 & $33 \%$ \\
\hline Ban on punitive damages & 38 & 10 & $26 \%$ & 6 & $5 \%$ \\
\hline Annual liability caps & 34 & 12 & $35 \%$ & 5 & $4 \%$ \\
\hline Ban on class action suits & 27 & 2 & $7 \%$ & 3 & $3 \%$ \\
\hline Elimination of third party payer suits & 0 & 0 & $0 \%$ & 0 & $0 \%$ \\
\hline
\end{tabular}

${ }^{\star}$ See Methods for explanation of policy themes. 
Table 2 Frames used to define the problem of tobacco in newspaper coverage of the tobacco settlement debate, 1997-98

\begin{tabular}{lllll}
\hline & $\begin{array}{l}\text { Number of } \\
\text { articles in which } \\
\text { frame appeared }\end{array}$ & $\begin{array}{l}\text { Percentage of } \\
\text { articles in which } \\
\text { frame appeared }\end{array}$ & $\begin{array}{l}\text { Number of } \\
\text { articles in which wam } \\
\text { framinant }\end{array}$ & $\begin{array}{l}\text { Percentage of } \\
\text { articles in which } \\
\text { frame was } \\
\text { dominant }\end{array}$ \\
\hline Kids & 95 & $81 \%$ & 64 & $55 \%$ \\
David v Goliath & 41 & $35 \%$ & 11 & $9 \%$ \\
Outside intruder & 29 & $25 \%$ & 6 & $5 \%$ \\
Costs of smoking & 28 & $24 \%$ & 6 & $5 \%$ \\
Drug delivery device & 24 & $21 \%$ & 7 & $6 \%$ \\
Smokers at risk & 23 & $20 \%$ & 5 & $4 \%$ \\
Deceit/manipulation & 20 & $17 \%$ & 6 & $5 \%$ \\
Killer/corporate liability & 17 & $15 \%$ & 0 & $0 \%$ \\
Non-smokers' rights & 5 & $4 \%$ & 0 & $0 \%$ \\
\hline
\end{tabular}

${ }^{\star}$ Frames are adapted from previous analysis by Menashe and Siegel. ${ }^{1}$

Table 3 Trends in prevalence of dominant tobacco control frames, 1985-1998

\begin{tabular}{llcc}
\hline & \multicolumn{2}{l}{$\begin{array}{l}\text { Percentage of articles in which frame appeared as the dominant } \\
\text { frame }\end{array}$} \\
\cline { 2 - 4 } & $\begin{array}{l}1985-1992 \\
(n=81)\end{array}$ & $\begin{array}{l}1993-1996 \\
(n=96)\end{array}$ & $\begin{array}{l}1997-1998 \\
(n=117)\end{array}$ \\
\hline Frame* & $30 \%$ & $20 \%$ & $0 \%$ \\
Non-smokers' rights & $23 \%$ & $7 \%$ & $0 \%$ \\
Killer/corporate liability & $22 \%$ & $27 \%$ & $5 \%$ \\
Deceit/manipulation & $7 \%$ & $7 \%$ & $5 \%$ \\
Outside intruder & $4 \%$ & $22 \%$ & $55 \%$ \\
Kids & $4 \%$ & $10 \%$ & $6 \%$ \\
Drug delivery device & $4 \%$ & $2 \%$ & $4 \%$ \\
Smokers at risk & $4 \%$ & $1 \%$ & $9 \%$ \\
David $v$ Goliath & $2 \%$ & $3 \%$ & $5 \%$ \\
Costs of smoking & & & $5 \%$ \\
\hline
\end{tabular}

${ }^{\star}$ Frames are adapted from previous analysis by Menashe and Siegel. ${ }^{1}$ Prevalence of dominant tobacco control frames in newspaper articles for the periods 1985-1992 and 1993-1996 are from analysis by Menashe and Siegel.

the articles, while the non-smokers' rights frame appeared in only $4 \%$ (5) of the articles.

In comparing the frequency of tobacco control frames in the tobacco settlement articles of 1997-98 and in the tobacco articles from 1985-96, the most striking trend was the steady increase in the prevalence of the kids frame (table 3). The kids frame appeared as the dominant frame in $4 \%$ of articles during the period 1985-92, 22\% during the period 199396 , and $55 \%$ during the period 1997-98. Also striking was the steady decline in the prevalence of the killer/corporate liability frame. The killer/corporate liability frame appeared as the dominant frame in $23 \%$ of articles during the period 1985-92, 7\% during the period 1993-96, and 0\% during the period 1997-98.

The non-smokers' rights frame also steadily declined in prevalence (table 3). This frame was the dominant frame in $30 \%$ of articles during the period 1985-92, 20\% during the period 1993-96, and 0\% during the period 1997-98.

\section{Discussion}

The results of this content analysis provide the first systematic description of the themes and frames used to portray the national tobacco settlement debate of 1997-98 in the news media. We found that the major theme in the newspaper coverage of the tobacco settlement debate was money, that the discussion of the public health policy aspects of the settlement focused on federal regulation of tobacco and largely ignored the potential role of states and local communities in controlling and preventing tobacco use, and that although the general issue of tobacco industry immunity was widely addressed, the specific alterations to the civil justice system that were being considered in the debate were not presented to the American public. We also found that the problem of tobacco was largely framed as one of youth smoking, that tobacco was almost never portrayed as a deadly product, and that the issue of secondhand smoke was rarely addressed.

While there was extensive discussion of the new revenue that would be provided in a tobacco settlement and of the way in which this revenue would be obtained (cigarette tax increases, price increases, and tobacco industry payments), there was very little discussion of how this money would be used to help achieve the goal of reducing tobacco related morbidity and mortality. The prevention and control of tobacco use was portrayed almost entirely as a federal issue. There was extensive discussion of the use of federal tax increases, FDA regulation of tobacco, and federal restrictions on tobacco advertising, but almost no discussion of policy and programme initiatives that states and local communities can take to control and prevent tobacco use. For example, four important programme/policy measures-allocation of revenue to fund antismoking campaigns, efforts to restrict youth access to tobacco, initiatives to support adult smoking cessation, and policies to protect non-smokers from secondhand smoke-received very little attention. In fact, the issue of providing revenue to support tobacco farmers received almost twice as much attention as any one of these four state and community level tobacco control interventions. It is important to note that although the FDA's tobacco regulations did contain provisions regarding youth access to tobacco and a discussion of FDA authority to regulate tobacco could therefore be construed as addressing youth access to tobacco, the tobacco settlement contained specific provisions to directly restrict youth access and these provisions received little discussion.

The newspaper articles provided extensive coverage of the general issue of potential tobacco industry immunity that played a critical role in the settlement debate. However, there was little discussion of the four specific alterations in the civil justice system that were debated: (1) elimination of future class action lawsuits against tobacco companies; (2) elimination of punitive damages against the tobacco industry in future lawsuits; (3) elimination of third party payer suits against the industry; and (4) annual liability caps on damages awarded in tobacco litigation. Thus the public was not truly made aware of the implications of the proposed tobacco legislation for the American civil justice system. The public was unable to appreciate the degree to which the proposed legislation would have interfered with the ability of American citizens to effectively pursue claims against the tobacco companies in the future. It is possible that the media's failure to address the technical legal details of the proposed settlement's immunity provisions simply reflects the media's reluctance to provide such 
specific coverage in general news reporting; nevertheless, the effect of the inability or unwillingness of the media to address these technical issues was that the public's understanding of the immunity provisions was quite incomplete.

The way in which the themes of the proposed national tobacco legislation were portrayed by the media has important public health implications. First, future discussions of comprehensive tobacco policy must be driven not by a general discussion of the need to extract tobacco industry payments and concessions but by a more specific discussion of the precise programme and policy mechanisms by which tobacco use is to be most effectively prevented and controlled. A more thorough discussion of the role of federal, state, and community level intervention is essential, and mechanisms must be developed to ensure that ultimately, tobacco control interventions are delivered at the community level. The public must not be led to believe that tobacco control is simply a federal issue. The public must understand that tobacco control is an important issue for every community. Without a public appreciation for the role of tobacco control as an integral part of community public health, support for tobacco control programmes will eventually erode.

Second, the public health community must consider the implications of the failure of media coverage to adequately portray the changes in the civil justice system that were an integral part of the proposed tobacco settlement. The public was never engaged in a meaningful discussion of the implications of such changes for the pursuit of justice by American citizens. However, the public has strong opinions on these issues. Public opinion polls have revealed that the public opposes eliminating class action lawsuits against tobacco companies ( $31 \%$ support) or limiting annual liability of tobacco companies from lawsuits (41\% support).$^{29}$ Public opinion must be fully incorporated into a discussion of such substantial changes in the civil justice system. However, based on our findings, the media cannot be relied upon to meaningfully engage the public in a full discussion of these issues. Public health groups might wish to consider the implications of proposing such substantial changes to the civil justice system in the absence of a meaningful way for public opinion to be brought into such a debate.

Our analysis of the dominant frames in the 117 articles shows that tobacco use was defined as a problem primarily because youths are smoking and the tobacco companies are marketing their products to youths. The debate over national tobacco policy in 1997-98 was largely a debate about youth smoking. Tobacco use was almost never defined as a problem simply because the product is deadly. In other words, tobacco was defined as a problem because of the age of individuals using the product, rather than because of the nature of the product itself. Combined with earlier findings on the prevalence of various tobacco control frames in newspaper articles between 1985 and $1996,{ }^{1}$ this paper suggests a gradual, but consistent shift in the definition of the tobacco problem from a problem of a deadly product to a problem of a product that is used by, and marketed to, minors. This shift in the way the tobacco issue has been framed in the media probably reflects a shift in the way the issue has been framed by public health leaders. ${ }^{30}$ Glantz has argued that the tobacco control community has recently shifted its emphasis from focusing on smoking as a problem because tobacco kills to defining smoking as a problem simply because children are smoking. ${ }^{30}$

The "kids" frame has no doubt been an effective hook to gain substantial media coverage of the tobacco issue and has helped to achieve widespread media attention and public awareness of tobacco as a public health problem. Nevertheless, this shift in the way that the tobacco problem is defined has important public health implications. First, defining the problem of tobacco as a youth issue reinforces the tobacco industry's framing of tobacco use as an adult behaviour. It fails to challenge social norms regarding tobacco promotion and use, because it implies that the promotion and use of this deadly product are appropriate as long as young people are not involved.

Second, the kids frame implies interventions that focus exclusively on minors, ignoring interventions that aim to create broader social and environmental changes in society. Programmes such as adult smoking cessation efforts and secondhand smoke regulations, which can actually lead to a reduction in youth smoking by changing social norms regarding tobacco in society, are not viewed as being of primary importance when the issue is framed solely as one of youth smoking.

Public health practitioners will need to weigh the advantages of using the kids frame as a means of gaining access to the media against the potential disadvantages of framing the tobacco issue in a way that reinforces the tobacco industry's framing of smoking as an adult behaviour, fails to adequately challenge existing social norms, and perhaps makes it more difficult to advance a broader array of social and environmental changes necessary to alter social norms regarding tobacco use.

The virtual absence of the "non-smokers' rights" frame is significant because it reinforces the tobacco industry's framing of smoking as an issue of personal choice and individual rights. The limited appearance of the "costs to society" frame is ironic because the very premise for the state lawsuits against the tobacco industry is that tobacco related illnesses are costing the states billions of dollars in health care expenditure.

\section{LIMITATIONS}

There are several limitations to our findings. First, only one newspaper was examined, and the Washington Post may not be an accurate reflection of how the tobacco settlement debate was portrayed in other newspapers. In particular, we are not able to comment on the framing 
of the tobacco settlement debate in local newspaper coverage. Our decision to restrict the analysis to the Washington Post was based on our desire to present a comprehensive account of the coverage of the tobacco settlement debate in the most influential newspaper for congressional policy makers. In doing so, we recognise that this paper may not necessarily reflect the way in which the tobacco settlement debate was portrayed in state based and local newspapers. In addition, our conclusions regarding trends in tobacco frames were based on a comparison of articles from two newspapers (the Washington Post and the New York Times) between 1985 and 1996 and only one newspaper (the Washington Post) during 1997 and 1998. We have no reason to believe that the trends we identified would have been any different had we sampled the New York Times, but caution is still called for in interpreting the significance of the observed trends.

Second, the classification of the tobacco control frames is a subjective process, and there were initially some discrepancies between the two reviewers.

Third, it is possible that the framing of the tobacco issue and the policy themes discussed may have been different in editorials and op-ed pieces. By excluding these pieces, we may have missed a piece of the picture of the portrayal of the tobacco settlement debate.

It is important to note that our purpose here is not to criticise the media's coverage of the tobacco settlement. We are simply trying to characterise this coverage and to consider the potential implications of the way the debate was framed. Whether the media are at fault or not, public health practitioners must understand the way the public is perceiving the issues and must incorporate this understanding in devising strategies to gain support for tobacco policies in the future.

Despite these limitations, the pattern of many of our findings is so strong that there is little chance for significant misinterpretation. In particular, the dominance of the money issues in the discussion of tobacco legislation and the dominance of the kids frame and near absence of the killer and non-smokers' rights frames are clear. Future discussion of national tobacco policy should be informed by these findings.

1 Menashe CL, Siegel M. The power of a frame: an analysis of newspaper coverage of tobacco issues-United States, 1985-1996. F Health Commun 1998;3:307-25.

2 Wallack L, Dorfman L, Jernigan D, et al. Media advocacy and public health: power for prevention. Newbury Park, California: Sage Publications, 1993.
3 Chapman S, Lupton D. The fight for public health: principles and practice of media advocacy. London: BMJ Publishing and practice of

4 Entman R. Framing: toward clarification of a fractured paradigm. $\mathcal{F}$ Commun 1993;43:51-8.

5 Iyengar S. Is anyone responsible? How television frames political issues. Chicago: University of Chicago Press, 1991.

6 Ryan C. Prime time activism: Media strategies for grassroots organizing. Boston: South End Press, 1991.

7 Schon DA, Rein M. Frame reflection: toward the resolution of intractable policy controversies. New York: Basic Books, 1994.

8 Wallack L, Dorfman L. Media advocacy: a strategy for advancing policy and promoting health. Health Educ $Q$ 1996;23:293-317.

9 Dorfman L, Woodruff K, Chavez V, et al. Youth and violence on local television news in California. Am 7 Public Health 1997;87:1311-16.

10 Wagenaar AC, Streff FM. Public opinion on alcohol policies. F Public Health Policy 1990;11:189-205.

11 Fine TS. The impact of issue framing on public opinion toward affirmative action program. Soc Sci f 1992;29:32334

12 Slovic P, Fischhoff B, Lichtenstein S. Response mode, framing, and information-processing effects in risk assessment. ing, and information-processing effects in risk assessment. ency. San Francisco: Jossey-Bass, 1982:21-36.

13 Vaughan E, Seifert M. Variability in the framing of risk issues. F Soc Issues 1992;48:119-35.

14 Smith $\mathrm{T}$. That which we call welfare by any other name would smell sweeter: an analysis of the impact of question wording on response patterns. Public Opin O 1987;51:7583.

15 Meyerowitz BE, Chaiken S. The effect of message framing on breast self-examination attitudes, intentions, and on breast self-examination attitudes, int

16 Rothman AJ, Salovey P, Antone C, et al. The influence of message framing on intentions to perform health behaviors. F Exp Soc Psychol 1993;29:408-33.

17 Vookles J, Carr J. The effects of message framing manipulations on AIDS preventive behavior. AIDS Weekly 1993;16.

18 Wilson DK, Purdon SE, Wallston KA. Compliance to health recommendations: a theoretical overview of message framing. Health Educ Res Theory Pract 1988;3:16171 .

19 Wilson DK, Wallston KA, King JE. Effect of contract framing, motivation to quit, and self-efficacy on smokin reduction. F Appl Soc Psychol 1990;20:531-47.

20 Jacobson PD, Wasserman J, Raube K. The politics of antismoking legislation. 7 Health Polit Policy Law 1993; 18:787-819.

21 Chapman S. The news on smoking: newspaper coverage of smoking and health in Australia, 1987-88. Am f Public Health 1989;79:1419-21.

22 Schwartz J, Torry S. Tobacco firms negotiating package settlement of suits: cigarette makers seek protection from liability. The Washington Post 1997 Apr 17: Sect A1:1.

23 Schwartz J, Torry S. Tobacco pact calls for strict federal controls. The Washington Post 1997 Jun 21: Sect A1:1.

24 Torry S, Schwartz J. Tobacco agreement needed nudge from White House: President's aide suggested idea to end three-month standoff over punitive damages. The Washington Post 1997 Jun 23: Sect A6:6.

25 Fox BJ, Lightwood JM, Glantz SA. Analysis of the proposed resolution of the United States tobacco litigation. San Francisco: University of California, San Francisco, Institute for Health Policy Studies, 1997.

26 Schwartz J. Advisory panelists strongly critical of tobacco deal. The Washington Post 1997 Jun 26: Sect A3:3.

27 S.1415. Universal Tobacco Settlement Act: A bill to reform and restructure the processes by which tobacco products are manufactured, marketed, and distributed, to prevent the use of tobacco products by minors, to redress the adverse health effects of tobacco use, and for other purposes. Introduced into the United States Senate on November 7, 1997.

28 Torry S, Dewar H. Senate GOP kills McCain tobacco bill. The Washington Post 1998 Jun 18: Sect A1:1.

29 Blendon RJ, Young JT. The public and the comprehensive tobacco bill. FAMA 1998;280:1279-84.

30 Glantz SA. Preventing tobacco use-the youth access trap [editorial]. Am f Public Health 1996;86:156-8. 